\title{
Multilateralism and Regionalism in International Trade Law
}

\author{
JÁNOS MARTONYI*
}

\begin{abstract}
International trade has been tested by a growing number of economic, political, ideological, institutional and legal challenges. On the one hand, the future of the global trading system depends largely upon the development of all these 'external', uncertain and unpredictable risks and opportunities of various natures. On the other hand, international trade and the functioning of the global trading system is one of the major factors that have a significant impact upon the shaping of the present and future world order.
\end{abstract}

Keywords: multilateralism, regionalism, international trade law, free trade

Trade has always been the generating force of economic growth, employment, prosperity and progress of humanity. The forms, the objects, the technics and the rules have always been changing throughout history. These transformations are rapidly accelerating but the substance and function of exchanging the products of human activities on a local, regional and global level have remained essentially the same - creating wealth and promoting welfare. What used to be limited to the exchange and physical movement of goods has been extended to services of all kinds and now more and more engulfs the flow of data.

The fundamental shift in the relation between the trade in goods, the trade in services and the flow of data, due to the breath-taking development of technology - the new phenomenon of 'deep-tech' and all that it entails, create the impression that trade is losing its importance and the main transformation is taking shape outside the traditional sense of trade. However, deep-tech does not diminish the role of trade in the widest sense, i.e. exchanging everything that is created physically or intellectually by humans, including algorithms for robotization, automation or ultimately artificial intelligence.

It is true that the volume of goods moved around the world, in particular the goods carried by sea, is not increasing but is on the wane, in relative to trade in services and also the global economic growth. At the same time, supply chains become even more complex, increasingly relying on new technologies, substituting data for components. All in all, the ancient devise 'navigare necesse est' is still valid and in a more abstract sense, it is more relevant than ever.

The deep-rooted and sweeping transformation in the nature, structure and forms of international trade has resulted in both macroeconomic theory and political doctrine becoming fundamentally divided on a long range of issues, previously considered as simple evidences based on conventional wisdom.

Are bilateral trade balances still (or again) relevant or in a multilateral world economic system bilateral imbalances may be considered irrelevant? What are the main causes of perennial bilateral deficits? Are there general macroeconomic reasons behind these imbalances, such as excessive spending and saving on the other side? Or it is the 'manipulated' value of some countries' currency, or the unfair rules established by

* Former minister of foreign affairs of Hungary and professor emeritus, University of Szeged, nmjt@juris.u-szeged.hu. This thematic issue (Missed and new opportunities in world trade. Eds. Csongor István Nagy \& Zoltán Víg) was published as part of the research project of the HAS-Szeged Federal Markets ‘Momentum’ Research Group. 
multilateral or by regional agreements or, indeed, their persistent violations that are to be primarily blamed for all these disequilibria and controversies.

Conflicting economic theories, diverse and opposing ideas and arguments are swirling around in academic, as well as, in public discourse and make - directly and immediately their way to heated political debates. Correlation is confused with causation and vice versa. Political ideologies step in and make a once scholarly and intellectually attractive, but in broader political debates somewhat neglected, subject the area of fiercest debates a battlefield of ideological and political clashes. TTIP, TPP, NAFTA are only some of the cases in point. The war is therefore economic, political and cultural alike and the conflicts between national interests are compounded by deep ideological divides that are made instrumentals by political movements for their own political purposes. The conflict between the regulatory autonomy or sovereignty of states and the beyond the border regulatory efforts of the new generation free trade agreements also reflects in the most spectacular manner the deepening ideological divide which is ultimately rooted in the diametrically opposing views relating to the tackling of globalization and the visions on global governance.

The internal conflicts and challenges of the world trading system are aggravated by the geopolitical challenges, tectonic shifts and rumbles from all around the world. The 'great shift' in the economic and geopolitical power structure of the world, the absence of a single dominant power or hegemon, the growing fragmentation of the economic, geopolitical and cultural world order, the rise of a multi-actor, multi stake-holder world, the re-emerging spheres of influence, the growing antagonisms and all the risks and threats entailed by them supply the basic framework and background for an international trading system fighting for its survival and for the saving of its tremendous achievements of the last 70 years.

The role of legal scholarship in this situation, characterized also by excessive rhetoric, should initially be, to calm down the excitement, 'calmer les esprits' and to take an objective, reasonable and balanced approach, distancing itself from ideological motives and sentiments. ${ }^{1}$ Thorough analysis must be conducted at the same time, based upon reliable research and data in order to lay down the groundwork for future rule-making on local, national, regional and global level.

The global trading system, as established and developed by international trade law, stands on two interconnected pillars: International - multilateral and regional (bilateral) rule making and the adjudication of disputes on the basis of all these regulatory instruments.

It is well known that the multilateral trade regulations came to a standstill around 20 years ago and since then, they seems to be in a frozen state. Minor achievements have been made, such as the Trade Facilitation Agreement (Bali, 2013) or the Information Technology Agreement (extended in Nairobi, 201 this being the first major tariff cutting deal on an MFN basis since 1996), but most of the original aspirations of the Doha Round simply have failed and are not to be expected to materialize even at a longer term.

The substantial increase in the number of participants in the global game, the changes in their economic weight and political clout and the absence of timely adaptation to them certainly has contributed to the deadlock in the multilateral rule-making. Another reason is the over-stretching of the scope or coverage of the regulations. The existing structure could no longer carry the multiplied weight of more and more targeted areas of law-making. On a more general level and in a deeper context, the freezing of the multilateral regulatory 
process also reflects the overall gridlock in the functioning of the global institutions or global governance.

The realistic objective that can now be set for the future development of the multilateral regulation of world trade is, first and foremost, the preserving and maintaining of the present system with all the substantial achievements. At the same time, the 'global acquis' of the regulatory system should and can be improved, developed and aligned with new demands and realities in some specific, limited areas. This has been the case in recent years. 'Save what we have', 'maintain it in workable shape' and 'keep the power dry' for the future can be the basic aspirations for the multilateral (global) rule-making in the present situation. Developments on other levels of regulation will further unfold, and are in many fields equally or even more suited to tackle the issues of international trade which itself, as has been seen, happens to be in deep and accelerating transformation. It is not only trade in the widest and more abstract sense that is rapidly changing, but also the social, political and economic demands and expectations are intensifying and have an even stronger impact upon all kinds of rule-making.

The multilateral trade regulation seems to have reached its limits which also appear to be in line with the apparent, structural or conjectural?, slowing down of globalization whilst the other pillar of the world trading system is still in fairly good shape and functions satisfactorily. The dispute settlement system of the WTO is often referred to as the 'bright spot' of the international trading system ${ }^{2}$ handling a growing number of complex and serious disputes between various members of WTO with a very high ratio $(90 \%)$ of compliance. The freezing of the rule-making branch of the system and the unfulfilled needs for adjustment and development of the rules has obliged the dispute resolution mechanism, in a way, to take over some of the tasks of the regulation and has to resolve issues that should normally be tackled by the organic development of the legislative process. The DSS of the WTO has therefore become the 'victim of its own success' and is being flooded by disputes in growing number and complexity. The system is more and more overloaded. Non-trade issues are on the rise, panels and the Appellate Body are confronted with the need to balance between disgeneric values which make their task sometimes close to impossible. At the same time, it is mistaken to believe that the DSS, that is the judicial function, can take over not only part of the legislative function, but also the "whole pain of the world' from environment protection to labour law, from SPS to social welfare or from data protection to human rights. The result is the increasing length of the procedures and also the decrease in prompt compliance. ${ }^{3}$

The multilateral DSS remains to be the most successful area of the world trading system despite these and other challenges. It is not perfect, but is fair and efficient. This is the reason why the multilateral dispute settlement seems to be winning the 'competition' with the dispute settlement mechanisms of the regional trade agreements. There is an ongoing academic discussion on the relationship and the possible jurisdictional conflict between the two mechanisms but the 'vast majority of RTA - DSMs have not been used at all', and even the 'FTA partners continue to use the WTO dispute settlement mechanism to resolve disputes between them'. ${ }^{4}$ One of the reasons for this preference for the WTO mechanism is no doubt its more legalistic character both in a substantive and in a

2 According to Sacerdoti 'the Dispute Settlement System (DSS) of the WTO continues to be considered a success story, and rightly so'. Sacerdoti (2016) 46.

3 Sacerdoti (2016) 47-49.

${ }^{4}$ Chase et al (2016) 610. 
procedural sense. The level of commitments, of course, differs as RTAs essentially aim to establish free trade with rights and obligations going well beyond the multilateral framework. The RTA - DSMs represent a wide range of models, from the pure politicaldiplomatic consultation to quasi-juridical and juridical systems or even a supranational model with direct effect of the decision adjudicating the dispute. ${ }^{5}$

The bright spot of the international trading system is, however, exposed not only to legal or procedural risks, but also to threats of general and fundamental nature. The dark clouds seem to be assembling on the horizon of the multilateral trading system. The general political and economic background also have a negative impact upon the judicial function. If this function is severely damaged, the overall system might receive a mortal blow. This is why all efforts must be developed in order to improve the dispute settlement system itself, adapting it to the new challenges, as well as to the political and economic realities.

Procedural improvements of the dispute settlement mechanism are needed and would, undoubtedly, be helpful. Whatever all these corrections will be, it must be clear, however, that the judicial function cannot, by itself save and secure the future of the multilateral trading system. The dispute settlement mechanism will be unable to appropriately fulfil its function without a solid legislative background, a basis of non-frozen rules, but evolve, adapt and develop according to the changes of the economic and political environment. The legislative and judicial function cannot be separated and are ultimately not only interlinked but also interdependent - one cannot live without the other. The ambitions for the revival of the rulemaking are still there and in the light of several statements it seems this time again, that hope is the last thing to die.

It cannot be contested that one of the main reasons for the rapid growth of RTAs has been the deadlock in the multilateral rule-making of WTO. At the same time, the differentiation of the multilateral system started well before the slowdown or the standstill in multilateral rule-making. It started with the birth of the system by including Article XXIV in the GATT, 1947. Exceptions from and derogations to the principle of equal treatment as implemented by MFN treatment widened both in law and in practice. WTO was established what used to be the general rule with limited exceptions became in reality the exception. ${ }^{6}$

This tendency was substantially accelerated by the special bilateral or regional (plurilateral) agreements based upon Article XXIV of GATT, Article V of the General Agreement on Trade in Service (GATS) or paragraph 2c of the Enabling Clause. The cornerstone of the multilateral system was the fundamental principle of equal treatment and the objective was to achieve progressive multilateral liberalisation, not to establish free trade - the purpose of the RTAs' was precisely the opposite. The objective here has been to establish special regimes, in most cases free trade between the parties. These agreements are by nature discriminatory granting special rights and benefits for their parties and by the same token, depriving the non-parties of the same rights and benefits.

By the end of 2016, there were 271 RTAs in force and notified to the WTO under the Transparency Mechanism of RTAs. ${ }^{7}$ In case agreements for goods and for services are counted separately the number of RTAs in force and notified was 461, while the overall number concluded and notified was 629. An unknown number of RTSs has not been notified

5 Chase et al (2016) 618-21.

${ }^{6}$ Martonyi (2015).

7 Recent Developments in Regional Trade Agreements, INT/SUB/RTA/153, July-December 2016. 
and therefore does not appear in the WTO Transparency Mechanism. 20\% of all RTAs in force are European, 17\% are in East Asia, 12\% in South-America and 9\% in the CIS region. The European Union has by far the highest number of RTAs. This number is in line with the EU's growing global outreach and will be further increasing. The United States (20) and China (14) follow the EU from a significant distance. The difference between the US and the Chinese number will soon be reduced and probably reversed due to the US step back from TPP (and perhaps other decisions to follow) and also as a result of the Chinese expansion, not only by filling the Asian vacuum created by the US, but also as part of a global geopolitical and economic ambition. The new bilateral or 'transactional' approach taken by the US and a more active Chinese trade policy driven by a growing assertiveness and a global vision and aspiration might reverse not only the relationship between the number of RTAs, but also affect the geopolitical and economic power balance between the two superpowers. Conclusions, however, should not be hastily drawn, given the complexity of the various factors and the uncertainty of developments. One, often somewhat disregarded, factor is the overwhelming advantage of the United States in the field of 'soft power'.

The RTAs growth has not been limited to their number but extended also their coverage as their scope has become more and more comprehensive, including provisions on intellectual property, competition, government procurement, investment and also regulation on the protection of human and animal health, environment, labour, social welfare and human rights. The overstretching of RTA coverage means that RTAs' world has been encountered by very similar challenges to those previously met by the multilateral regulation. The consequences of the extension of the regulated areas are, however, very much different in the multilateral rule-making and in the RTAs. RTAs are essentially free trade agreements, their regulations go much further 'beyond the border' and interfere much deeper with the national regulatory autonomy of the parties. This is where the serious political conflicts enter and turn into ideological clashes between the two sides of the deepening divide, increasingly instrumentalized for political purposes. This is the ideal terrain where 'globalists' and 'sovereigntists' can display and advocate their emotionally laden ideological and political prejudices, This can jeopardize the efforts aiming at the promotion of more free, more fair and more rule-based trade - rules that also have the basic function to protect and to safeguard the interests of the smaller and the weaker.

One way of easing the tension created by conflicting world visions could be to exercise more restraint in the widening of the scope of the agreements, the original function of which happened to be the promotion of free and fair trade. Political controversies are, in any case, hard to avoid, given not only the opposing ideological convictions, but also the underlying material, indeed, economic interests. ${ }^{8}$ It is also to be noted that quite frequently the same political and societal movements that demand respect for the regulatory sovereignty of nations strongly request the validation of social, labour and human rights for other countries, hence the inclusion of such provisions in the agreements.

Geographic proximity, economic policies, supply chains and geopolitics are the four drivers behind the establishment and shaping of RTAs and for at least a decade, the third and fourth factors have steadily been gaining importance. At the beginning of RTAs, it was clearly the geographic proximity was most visible factor - free trade areas or customs unions were essentially developed between or among neighbouring countries. Economic 
and social philosophy determining the political, social order as well as the economic and trade policies of the potential partners of an RTA also used to play a decisive role, as free trade was (and still is) unimaginable without a certain level of market economy and, accordingly, WTO membership. RTAs have been progressively establishing free trade and increasingly have come into being between not only geographically remote countries, but also parties whose economic, social and political orders show significant discrepancies. ASEAN was the first, but not the last evident example for this, where the ideological diversity' is compounded by the huge differences in the level of economic development. (Laos and Singapore.) Now, new RTAs have been concluded or are being negotiated between parties separated both by geographic distance and political philosophy e.g., EUVietnam, China and Chile or Switzerland.

Both the regional and the global economy are now based on supply chains that are now the major factors in the establishment of RTAs. On the other hand, RTAs themselves buoy up supply chains by stimulating and facilitating the free movement of goods and services becoming part of the supply as well as value chains. Hopefully be able to avoid the catastrophic consequences of a long-standing and well-functioning free trading regime, a single market, ceases to exist can be avoid thereby disrupting innumerable vital supply chains developed over several decades between the EU and the United Kingdom. ${ }^{9}$

In line with the general geopolitical developments, in particular the exacerbation of power struggles and confrontations of economic interests, the geopolitical factors also have a significant impact upon the establishment of RTAs. The best well-known example is the TPP where the original geopolitical objective of the United States was evident: The creation of an economic area, to develop closer ties with all the other 11 Asian, North and LatinAmerican nations and exclusion of China, the great geopolitical rival. The withdrawal of the US will also have geopolitical consequences, precisely the opposite of what was the original intent. China will likely take the place of the US and that will not only shift most of the economic benefits to the Middle Empire but it will re-enforce the Chinese geopolitical position and power in and well beyond the Asian region. Whether the economic withdrawal can be off-set by increasing military capabilities and power is an open - and somewhat ominous - question.

There is an older and closer demonstration of the sometimes preponderant role of geopolitics in creating RTAs. It is the European integration process where the original purpose was preponderantly political. Only after the treaty on the European Defence Community was voted down by the French National Assembly in 1954 was the idea of progressively creating an economic integration and thereby laying down the economic basis for an ultimate political union of Europe ('finalité politique') was put on the table by ingenious 'technocrats' like Jean Monnet. In doing so, he also invented the great technique of the 'méthode communautaire' that has been the key driver of the organic and incremental development of the European construction for at least for half a century. It is another question that the 'technocratic' approach has now been exhausted, in part because of its excessive overreach creating thereby problems that it could not resolve. Again, a 'victim of its own success'. Now it is high time to revert to the origins and to the somewhat forgotten principle of the 'finalite politique', adapted to the new situation in the world, primarily in the external relations of Europe. 
Whatever are the key drivers of the RTAs, they show a very high level of diversity, not only because of the differing factors and purposes behind them, but also due to the very different historic, economic and political situations in which they come into being. They are diverse in their coverage, structure, legal techniques, substantive provisions, rights, obligations, dispute settlement mechanisms and hence are not easy to be classified in various groups or models. This reflects the growing differentiation of the overall trading system starting originally within the multilateral framework, and later continued and deepened by the spreading of all sorts of bilateral, regional, plurilateral free trade agreements (as well as customs unions). However, behind this overwhelming trend of differentiation and fragmentation, there are apparent commonalities, principles and general features that may represent the groundwork for a future re-unification of the international trade rules. It should not be forgotten that the historic and legal background for the establishment of GATT was the sophisticated network of bilateral trade agreements based upon the MFN treatment that was ingeniously multilateralized in the new situation after the Second World War.

All these developments taking place in the international trading system reflect and demonstrate the general economic and geopolitical trends. Globalization slows down but goes on, regionalization, localisation is on the rise, but is intertwined with universal and common elements.

Geopolitical power and responsibility progressively devolve to regional levels, the diffusion of power decentralizes governance and rule-making but global risks and opportunities demand common action and universal (multilateral) rule-making.

These two competing and, at the same time, complementary tendencies are present not only in geopolitics, in the global economy and in the international trading system, but also in what is called 'soft power' or, indeed, culture in the widest possible sense. Culture tends to be belittled as the ultimate mover of all the other areas as the majority of attention is focused upon the economic and geopolitical (including military might) parts of the equation. 'It is culture that matters', culture essentially creates and forms economy, politics and all the other areas of human and social activities.

Rule-making is part of culture and as such does not only reflect, but also develops and shapes geopolitics as well as the economy. If this is true, then it is possible not only describe and analyse what is going on and why, but there is the possibility, the capability and the responsibility - by local, national, regional and universal rule-making - to influence, to shape and to improve the world's security, stability and prosperity.

Rules are getting more universal and fragmented at the same time, the world which was supposed to be flat is more and more divided, and power is more devolved. The economy and trade is inherently interdependent and multilateral but regional and bilateral endeavours increasingly pervade the whole system. Culture is diverse, collective identities differ (dialogue, not clash!), but it cannot dispense with some universal values that many believe, are of absolute nature. In this complex, tumultuous competition trade, free, fair and rule-based trade with a strong multilateral dimension has a vital role to play.

\section{LITERATURE}

Chase, Claude, Yaovich, Alan, Crawford, Jo-Ann and Ugaz, Pamela, 'Mapping up dispute settlement mechanism in regional trade agreements - innovative or variations on a theme?' in Acharya, Rohini (ed), Regional Trade Agreements in the Multilateral Trading System (CUP 2016) 608-702.

Martonyi, János, 'Transatlantic Trade and Investment Partnership Negotiations and its Consequences for the European Union' (2016) XXVII. FIDE Congress, Budapest 144-58. 
Martonyi, János, 'The Decline of Equal Treatment in World Economy' (2015) 1 Foreign Trade, Legal Studies, 1-13.

Martonyi, János, 'Brexit. Brexit?' (2016) 1 ELTE Law Journal, 19-37.

Sacerdoti, Giorgio, 'The Future of the WTO Dispute Settlement System: Consolidating a Success Story' in Primo Braga, Carlos A., Hoekman, Bernard M. (eds) Future of the Global Trade Order (European University Institute and IMD 2016) 45-68.

Nagy, Csongor István, 'Free Trade, Public Interest and Reality: New Generation Free Trade Agreements and National Regulatory Sovereignty' (2018) IX Czech Yearbook of International Law 197-216, available at $<$ https://papers.ssrn.com/sol3/papers.cfm?abstract_id=3172064>.

Recent Developments in Regional Trade Agreements, INT/SUB/RTA/153, July-December 2016 $<$ https://www.wto.org/english/tratop_e/region_e/rtajuly-dec16_e.pdf $>$ accessed on 11 October 2017. 